\title{
A CAATINGA E A OPORTUNIDADE DE MITIGAÇÃO DAS EMISSÕES DE GASES DE EFEITO ESTUFA PELA ATIVIDADE PASTORIL
}

\author{
Aldivan Rodrigues Alves* \\ Ariosvaldo Nunes de Medeiros** \\ Albericio Pereira de Andrade ${ }^{* * *}$ \\ Rosa Toyoko Shiraishi Frighetto**** \\ Messias José Santos Silva******
}

RESUMO: A mudança climática como consequência da emissão antropogênica de gases de efeito estufa está entre os temas em evidência. A agropecuária é apontada como uma das fontes de emissões de gases de efeito estufa, em especial a pecuária que contribui com as emissões de metano $\left(\mathrm{CH}_{4}\right)$, de origem entérica e de dejetos, e a emissão de óxido nitroso $\left(\mathrm{N}_{2} \mathrm{O}\right)$ do solo de pastagens e da produção de grãos. Metano de ruminantes origina-se, principalmente, como produtos do processo realizado pelos microrganismos do rúmen. Estes microrganismos utilizam nutrientes do alimento ingerido como substrato e produzem diversos compostos como produtos desse metabolismo, dentre eles o metano. Dessa maneira, a emissão de metano está diretamente relacionada à dieta ingerida pelos animais ruminantes. A origem da emissão de óxido nitroso está relacionada aos dejetos de animais, sólidos e líquidos, pelo mecanismo de transformação da urina-ureia a $\mathrm{N}_{2} \mathrm{O}$. Para assegurar que a produção de animais ruminantes seja eficiente, sustentável e ambientalmente amigável, serão necessários métodos de alimentação mais eficientes e apropriados, assegurando o funcionamento eficiente do rúmen. A Caatinga tem ampla diversidade de árvores e arbustos que apresentam características que a difere como fonte de recurso forrageiro quando comparada com pastagens cultivadas, decorrente de seus aspectos nutricionais como a presença de compostos provenientes do

\footnotetext{
Doutor pelo Programa de Doutorado Integrado em Zootecnia (PDIZ), UFPB/UFRPE/UFC. Docente de Ensino Básico, Técnico e Tecnológico do Instituto Federal de Educação, Ciência e Tecnologia de Maranhão (IFMA), Campus Caxias, Brasil. E-mail: Aldivan Rodrigues Alves < aldivan.alves@ifma.edu.br>

** Doutor em Zootecnia, Docente permanente do Programa de Pós-Graduação em Zootecnia, Universidade Federal da Paraíba, Campus Areia (UFPB), Brasil .

*** Doutor em Agronomia, Docente permanente do Programa de Pós-Graduação em Zootecnia, Universidade Federal da Paraíba, Campus Areia (UFPB), Brasil.

**** Doutora em Química Orgânica, Embrapa Meio Ambiente - Empresa Brasileira de Pesquisa Agropecuária (Embrapa), Brasil Doutora em Química Orgânica, Embrapa Meio Ambiente - Empresa Brasileira de Pesquisa Agropecuária (Embrapa), Brasil.

***** Doutor em Zootecnia, Docente de Ensino Básico, Técnico e Tecnológico do Instituto Federal de Educação, Ciência e Tecnologia de Rondônia/Campus Cacoal, Brasil.
} 
metabolismo secundário das espécies vegetais e, portanto, pode refletir diretamente no desempenho animal e na emissão de metano.

PALAVRAS-CHAVE: Emissão de metano; Pequeno ruminante; Tanino; Nutriente.

\title{
CAATINGA AND THE OPPORTUNITY IN MITIGATING GREENHOUSE GAS EMISSIONS BY AGRO-PASTORAL ACTIVITIES
}

\begin{abstract}
Climatic changes caused by anthropogenic greenhouse gas emissions are the most significant themes at present. Agriculture and livestock have been identified as one of the sources of greenhouse gas emissions. This is especially true for cattle due to their emission of methane $\left(\mathrm{CH}_{4}\right)$, enterically-derived and from wastes, and to the emission of nitrous oxide $\left(\mathrm{N}_{2} \mathrm{O}\right)$ from pastures and grain production. Methane from ruminants is mainly the product of processes involving microorganisms in the rumen. They use nutrients from ingested food as substrates and produce several compounds as products of metabolism, methane included. The emission of methane is therefore directly related to ruminant animals' diet. The emission of nitrous oxide is related to animals' solid and liquid wastes through the transformation of urineurea into $\mathrm{N}_{2} \mathrm{O}$. Feeding methods have to be more efficient and adequate, warranting the rumen's correct functioning, so that the product of ruminant animals would be more efficient, sustainable and environmentally friendly. The Brazilian caatinga or shrubland has a wide range of trees and shrubs, and, therefore, forage sources with different characteristics from those of the common pastureland. The above is due to nutritional aspects such as compounds derived from secondary metabolism of vegetal species which may be directly perceived in the animal's performance and methane emission.
\end{abstract}

KEY WORDS: Emission of methane; Small ruminants; Tannin; Nutrient.

\section{INTRODUÇÃO}

A partir de 10 de março de 2005, o mapa geográfico e social do semiárido incorpora 1.132 municípios, enquadrados segundo um dos três critérios utilizados para essa classificação, quais sejam a pluviosidade média anual inferior a $800 \mathrm{~mm}$, índice de aridez de 0,5 calculado pela relação precipitações e a evapotranspiração potencial, e risco de seca acima de $60 \%$. Em conjunto, esses municípios totalizam 
uma área de $969.589,4 \mathrm{~km}^{2}$. O bioma Caatinga está inserido no semiárido (Figura 1), ocupa uma área de aproximadamente $844.453 \mathrm{~km}^{2}$, equivalendo a $54 \%$ da região Nordeste e 9,92\% do território nacional (Brasil, 2005). Engloba totalmente o Estado do Ceará (100\%), pouco menos da totalidade do Estado da Paraíba (92\%), do Rio Grande do Norte (95\%), e de Pernambuco (83\%), mais da metade do Estado da Bahia (54\%), do Piauí (63\%), quase metade de Alagoas (48\%) e de Sergipe (49\%), além de pequenas porções do norte de Minas Gerais (2\%) e do Estado do Maranhão (1\%) (BRASIL, 2005).

Segundo a classificação de Köppen (1936), o clima é considerado semiárido quente, com três tipos de clima (ARAÚJO FILHO et al., 2002), sendo BShw (semiárido com curta estação chuvosa no verão, entre dezembro e janeiro), BShw' (curta estação chuvosa no verão-outono, entre março e abril) e BShs (curta estação chuvosa no outono-inverno, entre maio e junho), com predominância de temperaturas médias anuais acima de $18^{\circ} \mathrm{C}$. Menezes e Sampaio (2000) afirmam que a distribuição espacial e temporal de chuva é muito heterogênea e com altas taxas de evapotranspiração, consequentemente apresentando déficit hídrica na maior parte do ano.

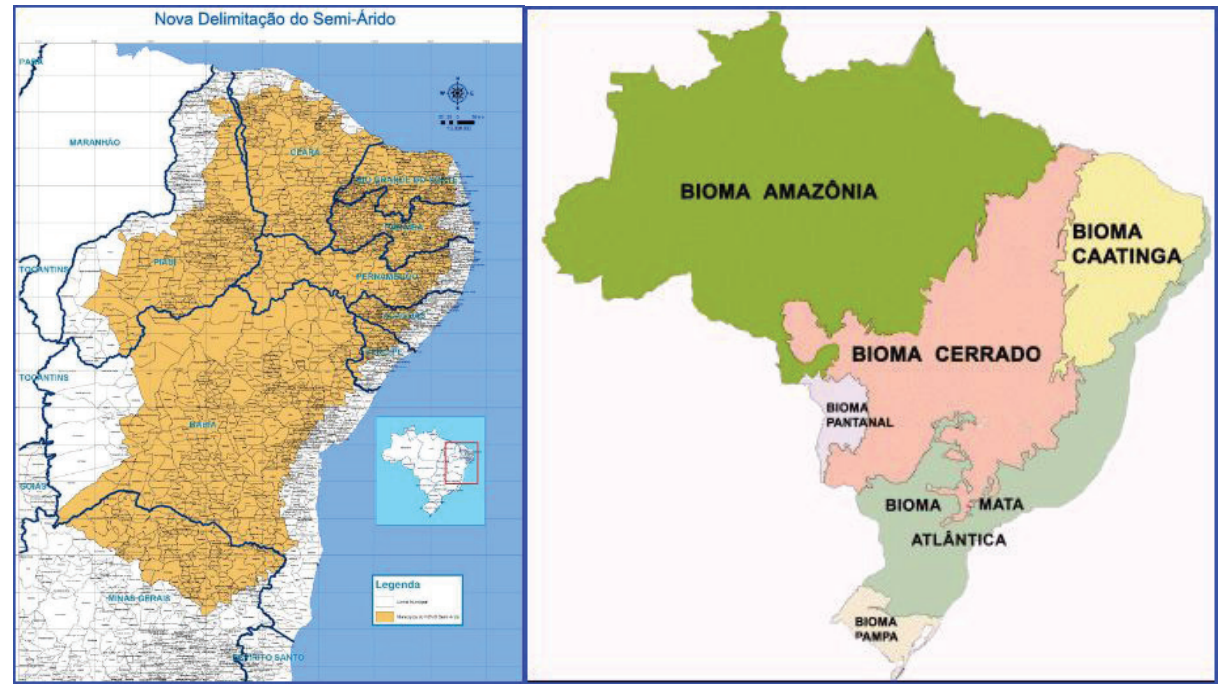

Figura 1. Mapa geográfico e social do semiárido (esquerda) e os biomas que compóem o território brasileiro (direita)

Fonte: (Brasil, 2005). 
A Caatinga apresenta diversidade em paisagens e vegetações, devido às variações geomorfológicas, climáticas, topográficas, e da própria ação do homem (TELES et al., 2006; CHAVES et al., 2008). De acordo com Drumond et al., (2000), e por Teles et al., (2006) para o sertão paraibano, esta vegetação é composta por espécies lenhosas e herbáceas, com predominância de vegetação de pequeno porte $(<3 \mathrm{~m})$, muitas dotadas de espinhos, sendo, geralmente, caducifólias, e por cactáceas e bromeliáceas, sendo 180 endêmicas, com densidade, frequência e dominância determinada pelas variações topográficas, tipo de solo e pluviosidade.

Ao realizar um levantamento da composição florística e fitossociológica de um fragmento da Caatinga na Paraíba, Pereira Júnior et al., (2012) constataram 3.495 indivíduos, distribuídos em 14 famílias, 26 gêneros e 37 espécies. A Caesalpinia pyramidalis Tul. (Fabaceae) apresentou a maior frequência e maior dominância. O Croton rhamnifolioides Pax \& Hollm. (Euphorbiaceae) apresentou a maior densidade e o maior índice de valor de importância e cobertura. Num estudo mais específico realizado num fragmento de Caatinga no município de Apodi (PB), Souza et al., (2013) identificaram 11 espécies pertencentes às sete famílias, com predominância de Leguminosae, sendo de portes arbustivas (4) e arbóreas (4), e três espécies herbáceas. Esses mesmos autores afirmam que há a predominância de arbustivas (20,98\%) e herbáceas (20,66\%), com dominância de poucas espécies arbóreas. Em estudo realizado no município de São João do Cariri ( $\mathrm{PB})$, Souza et al., (2013) classificam a vegetação como 78,20\% de herbáceas, 10,62\% de arbórea (Apocinaceae) e 12,23\% de arbórea (Leguminosae), num período em que a chuva foi em média de $7,7 \mathrm{~mm}$.

\section{POTENCIAL DA CAATINGA NA ATIVIDADE PASTORIL DE PEQUENOS RUMI- NANTES}

No Brasil a exploração de pequenos ruminantes, em grande parte, se concentra no bioma Caatinga na região semiárida, onde a vegetação nativa é predominante e serve de base alimentar desses animais. No entanto, esta atividade sempre esteve associada ao baixo uso de tecnologias que possam levar à melhoria do sistema produtivo e de seus produtos. 
Segundo Araújo Filho (2002), a produção estimada de fitomassa para pastagem é de $4.000 \mathrm{~kg} \mathrm{ha}^{-1}$, valores próximos também foram encontrados por Moreira et al. (2006). Souza et al. (2013) estimaram a disponibilidade de 1.674,5 kg MS ha ${ }^{-1}$ na região de São João do Cariri (PB), para o período em que a chuva média foi de $7,7 \mathrm{~mm}$, indicando a importância da suplementação mineral na dieta dos animais. Na região de Apodi (PB), Souza et al. (2013) descrevem a ocorrência, disponibilidade e a composição química para 2010 (julho e setembro) e 2011 (novembro e janeiro), encontrando valor médio em proteína bruta superior a $7 \%$ da matéria seca, considerado valor mínimo necessário para o crescimento da microflora microbiana. Carvalho Júnior et al. (2011) encontraram valores médios de proteína bruta variando de 6,62 (gramíneas) a 11,38 (dicotiledôneas), no estudo realizado em Patos (PB) no período de maio a setembro de 2007.

$\mathrm{Na}$ vegetação arbórea, até $90 \%$ do volume da fitomassa vêm de folhas de árvores e arbustos, enquanto que na área de Caatinga assavanada, o estrato herbáceo contribui com cerca de 80\% (ARAÚJO FILHO, 2002). Esse mesmo autor afirma que a forragem realmente aproveitada pelos animais varia em torno de $10 \%$ da produção na Caatinga arbórea a praticamente $100 \%$ na Caatinga assavanada. E aponta a existência de um paradoxo entre a qualidade e a disponibilidade estacional de forragem na área arbórea. Na estação das chuvas a qualidade da forragem é ótima, mas com disponibilidade baixa, enquanto que nas secas a disponibilidade é alta devido à queda das folhas, mas de baixa qualidade (ARAÚJO FILHO, 2002; MOREIRA et al., 2006).

Com o intuito de potencializar o uso da Caatinga na produção animal, estudos de manejo da vegetação foram conduzidos, resultando no aumento da produção de forragem (ARAÚJO FILHO et al., 2002; ARAÚJO FILHO; CRISPIN, 2002). Apesar disso, a produtividade animal em ganho de peso ficou em torno de 60 a 70 $\mathrm{kg} \mathrm{ha}^{-1}$ de peso vivo por ano. Moreira et al. (2006), no estudo realizado com bovinos na Caatinga pernambucana, confirmaram a diversidade da composição florística, ressaltando que poucas espécies são aproveitadas na dieta desse ruminante devido à baixa digestibilidade das espécies. A baixa digestibilidade também foi observada no estudo de Carvalho Júnior et al. (2011), realizado no município de Patos (PB) a partir do final da estação chuvosa, no período de maio e setembro. Leite et al. (2002) 
citam a determinação do valor nutricional e do consumo das dietas de ruminantes em pastagens nativas como um dos mais importantes e ao mesmo tempo um dos mais complexos aspectos da nutrição, devido à variação em quantidade e qualidade do recurso forrageiro disponível na Caatinga.

Um conhecimento preciso desta variação em quantidade e qualidade do recurso forrageiro disponível na Caatinga é extremamente necessário, com vistas à implementação de programas de suplementação alimentar que venha a propiciar a produção pecuária em estreita consonância com o potencial genético dos animais, $\mathrm{e}$ em níveis econômica e ecologicamente sustentáveis.

\section{EMISSÕES DE GASES DE EFEITO ESTUFA NA AGROPECUÁRIA}

A alteração do clima no planeta está cada vez mais evidente, influenciada pelo crescente aumento de gases como metano $\left(\mathrm{CH}_{4}\right)$, dióxido de carbono $\left(\mathrm{CO}_{2}\right)$, óxido nitroso $\left(\mathrm{N}_{2} \mathrm{O}\right)$, dentre outros, na atmosfera terrestre. Para entender a inserção da pecuária na conjuntura da mudança do clima, é preciso considerar de que forma ela contribui com as emissões antropogênicas de GEE (PRIMAVESI et al., 2015). A principal fonte de emissão de $\mathrm{CO}_{2}$, geralmente, é atribuída ao uso energético de combustíveis fósseis. No Brasil, a mudança do uso da terra é a principal parcela das emissões líquidas desse gás. A agropecuária é apontada como principal fonte emissora de $\mathrm{N}_{2} \mathrm{O}(84,2 \%$ do total emitido, 2010) ocorrendo principalmente por deposição de dejetos animais (BRASIL, 2016).

Segundo as estimativas de emissões constantes da Terceira Comunicação Nacional do Brasil à Convenção-Quadro das Nações Unidas sobre Mudança do Clima (Brasil, 2016), o setor da agropecuária é responsável por 74,4\% das emissões de $\mathrm{CH}_{4}$. Desse total, a emissão de $\mathrm{CH}_{4}$ proveniente da fermentação entérica de animais foi estimada, em 2010, em 11,16 $\mathrm{Tg}$ ano $^{-1}$ (Teragrama=milhão de tonelada), correspondendo a $89,9 \%$ do total de $\mathrm{CH}_{4}$ emitido pela agropecuária (BRASIL, 2016), sendo o gado de corte responsável por 75\% da emissão de $\mathrm{CH}_{4}$ devido ao tamanho da população bovina, seguida por gado de leite com $12 \%$. Ainda segundo a mesma fonte, os ovinos e caprinos foram considerados na categoria Outros animais 
devido à inexistência de informações, e a média default considerada foi de 0,359 Tg, correspondendo a 3,1\% do total de metano emitido pela pecuária.

Dessa forma, a exploração de ruminantes em pastejo também é considerada uma prática que pode contribuir com o efeito estufa através da emissão de metano produzido pelo processo de fermentação entérica (GOUVELLO et al., 2010). Segundo esses autores, o estudo mostrou que uma das alternativas para a redução da emissão de metano é através da intensificação dos sistemas de produção de carne. Foi também proposta a opção de melhoramento genético, associando forragem de melhor qualidade com animais geneticamente superiores, levando ao menor ciclo produtivo. Nesse contexto, estudos já indicam que as características inerentes à forragem contribuem para redução e/ou aumento da emissão de metano (LASSEY et al., 2008; KEBREAB et al., 2010).

O valor nutricional da forragem na Caatinga, citado por Leite et al. (2002), e a proposta de Araújo Filho (2014) sobre o manejo sustentável da pecuária na Caatinga, podem ser associados com o termo climate-smart agriculture. Este foi introduzido pela primeira vez com o conceito de produção sustentável, pela elevação da produtividade, pelo aumento da resiliência, pela redução das emissões de gases de efeito estufa (GEE), e pelo alcance da segurança alimentar e do desenvolvimento (FAO, 2010). Ainda não existe um protocolo-orientador específico, mas a aplicação prática desse conceito busca uma conjugação entre a produtividade e a redução de emissões de GEE (NEGRA et al., 2014). Nesse contexto, não podemos esquecer de associar as necessidades e prioridades dos pequenos produtores, ressaltado por Rosenstock et al., (2013), críticos dos modelos anteriores por excluírem os atores envolvidos na produção. Nesse sentido, será necessário conhecer a linha de referência (linha base) tanto da produtividade quanto de emissões envolvidas com as formas de produção utilizadas hoje na área da Caatinga, para então possibilitar a identificação de opções de mitigação. 


\section{ASPECTOS NUTRICIONAIS DAS FORRAGEIRAS DA CAATINGA}

Os aspectos nutricionais têm sido foco de diversos estudos ao longo dos anos na tentativa de otimizar a utilização da Caatinga, principalmente, de maneira mais eficiente e que apontem direcionamentos e/ou estratégias para melhorar a exploração dos pequenos ruminantes neste bioma (LIMA, 1996; LEITE et al., 2002; LIMA JÚNIOR, 2006; MOREIRA et al., 2006; SANTOS et al., 2010).

Estudos foram realizados nesse sentido (MOREIRA et al., 2006; MARQUES et al., 2014; LIMA JÚNIOR, 2006) visando determinar a composição química e digestibilidade da dieta de ruminantes na Caatinga, levando em consideração a extrusa desses animais (Quadro 1). Os resultados desses estudos demonstraram elevados teores de FDN, consideráveis valores de proteína e moderados valores para digestibilidade.

Quadro 1. Composição químico-bromatológica e coeficiente de digestibilidade de extrusa em pastejo na caatinga

\begin{tabular}{|c|c|c|}
\hline Nutriente & Teor $\left(\mathrm{g} \mathrm{kg}^{-1}\right)$ & Ref. \\
\hline MS & 156,7 a 231,1 & $\begin{array}{c}\text { Marques et al., (2014) } \\
\text { Moreira et al., (2006) }\end{array}$ \\
\hline PB & 88,1 a 123,4 & $\begin{array}{c}\text { Marques et al., (2014) } \\
\text { Moreira et al., (2006) }\end{array}$ \\
\hline FDN & 538,5 a 713,0 & $\begin{array}{c}\text { Marques et al., (2014) } \\
\text { Moreira et al., (2006) }\end{array}$ \\
\hline NIDIN & $710,8^{1}$ & Moreira et al., (2006) \\
\hline NIDA & $495,3^{1}$ & Moreira et al., (2006) \\
\hline DMS & 372,7 a 460,0 & $\begin{array}{c}\text { Marques et al., (2014) } \\
\text { Moreira et al., (2006) }\end{array}$ \\
\hline Taninos ligados & 1,40 & Lima Júnior (2006) \\
\hline
\end{tabular}

${ }^{1} \mathrm{~g} \mathrm{~kg}^{-1}$ de proteína 
Embora os teores de proteína bruta presente na vegetação da Caatinga, de modo geral, sejam elevados e atendam às necessidades dos animais quanto ao teor mínimo de proteína, durante um curto período (estação chuvosa) (SANTOS et al., 2010; CARVALHO JÚNIOR et al., 2011), uma avaliação do nitrogênio disponível para os microrganismos ruminais se faz necessário, uma vez que estas podem estar ligadas à parede celular (NIDA) e, consequentemente, atravessar o trato gastrintestinal intactos sem serem absorvidas (SANTOS et al., 2010). No período seco pode haver déficit de proteína, adverte Leite et al. (2002), pois com a maturação da vegetação ocorre diminuição da proteína e aumento de lignina.

Na classificação preconizada pelo CNCPS (The Cornell Net Carbohydrate and Protein System), as proteínas e os carboidratos são fracionados de acordo com sua biodisponibilidade e taxa de degradação. As proteínas são classificadas em fração prontamente disponível ( $\mathrm{A}$ = nitrogênio não proteico), fração de rápida degradação ruminal (B1 = peptídeos e oligopeptídeos), de degradação intermediária (B2 = proteína verdadeira), fração de lenta degradação ruminal (B3 = proteína associada à parede celular potencialmente disponível no rúmen) e fração indigestível (C = proteína insolúvel em detergente ácido). Da mesma forma, os carboidratos são classificados em frações A (açúcares simples) e B1 (amido e pectina), rapidamente degradáveis, fração B2 (carboidratos fibrosos potencialmente degradáveis) e fração C (carboidratos fibrosos não degradáveis) (SNIFFEN et al., 1992).

Cabral (2014) ao realizar o fracionamento de proteína de algumas espécies da Caatinga, expresso em percentual de proteína bruta, encontrou: 17,4 a 44,5; 10,2 a 38,4; 31,2 a 56,8; 1,3 a 5,8 e 1,1 a 6,5\% para as frações A, B1, B2, B3 e C, respectivamente. A fração A da proteína é importante para o crescimento dos microrganismos presentes no rúmen por ser o nitrogênio não proteico, substrato importante para seu metabolismo e crescimento, resultando em proteína microbiana para os ruminantes pela utilização na forma de $\mathrm{N}-\mathrm{NH}_{3}$. De acordo com Russell et al., (1988), a utilização de $\mathrm{N}-\mathrm{NH}_{3}$ pelas bactérias é diferenciada, enquanto as fermentadoras de carboidratos não fibrosos utilizam apenas um terço das fontes nitrogenadas na forma de $\mathrm{N}-\mathrm{NH}_{3}$, as bactérias fermentadoras de carboidratos fibrosos utilizam o $\mathrm{N}-\mathrm{NH}_{3}$ como forma preferencial de fonte nitrogenada. 


\section{ASPECTOS NUTRICIONAIS DAS FORRAGEIRAS QUE INFLUENCIAM NA EMISSÃO DE METANO}

O estudo de Cabral (2014) aponta elevada fração $B_{2}$, indicativo de disponibilidade intermediária de substrato nitrogenado no rúmen. De acordo com Waters (1992), esta fração por fornecer aminoácidos e peptídeos, juntamente com a fração B1, são importantes substratos para os microrganismos que fermentam carboidratos não fibrosos e que apresentam menor produção de $\mathrm{H}_{2}$ para serem utilizados na produção de metano ruminal, quando comparadas com as fermentadoras de carboidratos fibrosos.

Vale salientar também a presença da fração $C$ que representa a proteína não disponível associada à lignina, complexos tânicos proteicos e produtos da reação de Maillard, os quais resistem ao ataque das enzimas microbianas e do hospedeiro sendo, portanto, indisponíveis durante a passagem pelo trato gastrintestinal (WATERS, 1992). Ao verificar os teores proteicos encontrados nas extrusas dos ruminantes em pastejo na Caatinga e subtrair sua fração indisponível percebe-se a redução considerável na proteína disponível no rúmen. A limitação de nitrogênio reduz a fermentação da fibra (RUSSELL et al., 1992) e reduz o consumo da matéria seca (VAN SOEST, 1994).

A limitação de proteína, portanto, nas forrageiras nativas pode causar impacto no ambiente ruminal e, em determinado momento, reduzir a emissão de metano, e ao mesmo tempo permitir que suas frações de menor disponibilidade no rúmen possam ser aproveitadas no intestino pelo animal. No fracionamento de carboidratos, expresso em percentual de carboidratos totais (CHOT), Silvestre (2013) encontrou 10,4 a 50,6; 25,8 a 78,7 e 3,2 a 12,0\% para as frações A+B1, B2 e $\mathrm{C}$, respectivamente, nas espécies estudadas.

Segundo Russell et al. (1992), no metabolismo dos ruminantes tem que haver um sincronismo entre a fermentação dos carboidratos e dos compostos nitrogenados para maximizar o crescimento microbiano. As maiores frações A e B1 de proteína requerem a presença de carboidratos de rápida fermentação para que estas sejam incorporadas pelos microrganismos, e estas fontes de carboidratos podem reduzir o pH ruminal (RUSSELL et al., 1992; MENG et al., 2000). Quando o pH variou de 5,7 a 6,2 , a população de bactérias fermentadoras de carboidratos fibrosos 
diminuiu (RUSSELL et al., 1979). Já as bactérias fermentadoras de carboidratos não fibrosos persistiram até em variações de 4,6 a 4,9. Segundo Lana et al. (1998), as reduções no $\mathrm{pH}$ ruminal podem diminuir a produção de metano e amônia no rúmen, e estes efeitos apresentam potencial para melhorar a utilização de alimentos, principalmente de baixa qualidade.

No estudo realizado por Cabral (2014), as espécies vegetais apresentaram considerável fração A1+B1 de carboidratos (26,45 a 52,79\% nos CHOTs). No caso das leguminosas estes resultados podem ser consequência da presença de pectina que, embora seja um carboidrato estrutural, tem rápida fermentação. No entanto, contribui para formação e manutenção das concentrações de acetato ruminal e não o propionato (VAN SOEST, 1994), podendo assim contribuir para aumentar a emissão de metano.

A fração C dos carboidratos, por sua vez, promove o efeito físico de enchimento no rúmen, o que, segundo Van Soest (1994), pode refletir no efeito da repleção ruminal, isto é, tempo que o alimento permanece no rúmen, acarretando menor disponibilidade energética em virtude de sua característica de indigestibilidade, promovendo menor consumo potencial por unidade de tempo. Em ruminantes, a ingestão de matéria seca (IMS) é um dos principais fatores da produção de metano (g/dia) e geralmente há relação positiva entre a IMS e produção de metano (MOLANO; CLARK, 2008), decorrente do suprimento de substrato para os microrganismos metanogênicos.

Como a redução de $\mathrm{CO}_{2}$ a metano no rúmen desempenha importante função, agindo na remoção contínua do $\mathrm{H}_{2}$ resultante da fermentação da matéria orgânica (WEIMER, 1998), a digestibilidade dos nutrientes promove maior aporte de substrato para os microrganismos metanogênicos. No entanto, os valores dos coeficientes de digestibilidade na extrusa de ruminantes na Caatinga (MOREIRA et al., 2006; SANTOS et al., 2010) demonstram que estes coeficientes não apresentam valores elevados.

Lima (1996), ao estudar a digestibilidade de plantas da Caatinga, atribui a sua baixa digestibilidade a diversos fatores inibidores, entre eles o alto teor de tanino, encontrado em muitas espécies desse ambiente. No entanto, de acordo com Hook, et al. (2013), a concentração de tanino na dieta dos ruminantes pode causar efeitos negativos nas bactérias fermentadoras de carboidratos fibrosos e nas 
Archaea metanogênicas pela atividade antibacteriana e capacidade de redução na disponibilidade de nitrogênio, o que pode proporcionar redução na emissão de metano (CARULLA et al., 2005; PUCHALA et al., 2005).

Tiemann et al. (2008) observaram que a inclusão de leguminosas com elevados teores de tanino (Callinadra calothyrsus e Fleminga macrophylla) provocou diminuição na emissão de metano por carneiros em até $24 \%$, mas esse efeito foi associado à redução na digestibilidade da matéria orgânica e da fibra. Carneiros recebendo "Gamberin", um produto contendo $49 \%$ de tanino condensado (extrato solidificado das folhas de Uncaria gambir), apresentaram significativa redução na perda de energia como metano (\% da EB) e queda de $75 \%$ no número de protozoários ciliados (SARVANAN, 2000).

Santa Cruzetal. (2007), ao realizar a caracterização dos taninos condensados de espécies da Caatinga, encontraram baixa concentração de taninos totais (TT) na maniçoba $(1,64 \%)$, feijão bravo $(0,60 \%)$ e jureminha $(2,4 \%)$ e não foi detectada a presença de tanino condensado na espécie flor de seda. Estes autores ainda afirmam que a jureminha apresentou a maior concentração de tanino condensado total e a menor digestibilidade (42,9\%). Por outro lado, a flor de seda, espécie que não possui tanino condensado, apresentou a maior digestibilidade da matéria seca com 80,1\%. Trabalhos têm demonstrado que fatores sazonais, como a disponibilidade pluviométrica, interferem no teor de tanino das espécies (JACOBSON et al., 2005; MONTEIRO et al, 2006). As folhas de M. urundeuva e cascas de A. colubrina, no período chuvoso, apresentam maiores teores de taninos (MONTEIRO et al, 2006), assim como encontrado em Stryphnodendron adstringens (Mart.) Coville e $S$. polyphyllum Mart. as quais têm maiores produções de fenóis totais e taninos nesta mesma época (JACOBSON et al., 2005).

\section{ASPECTOS METABÓLICOS QUE INFLUENCIAM NA PRODUÇÃO DE METANO POR RUMINANTES}

Os ruminantes têm uma relação simbiótica estabelecida com os microrganismos ruminais pela qual os animais provêm os nutrientes e condições 
ótimas para a fermentação de alimentos e os microrganismos degradam as fibras. Os nutrientes ingeridos pelos animais estão na forma de carboidratos, proteínas e lipídeos. Na matéria seca das plantas, cerca de $75 \%$ corresponde a carboidratos. A fermentação microbiana quebra a molécula de carboidratos em açúcares simples, e os microrganismos usam esses açúcares como fonte de energia para seu crescimento e para produção de outras moléculas, como ácidos graxos voláteis (AGV) e gases (MORAN, 2005). A principal característica dos ruminantes que os diferencia de outros animais está na sua capacidade de utilizar alimentos ricos em carboidratos estruturais (celulose e hemicelulose) que, através da fermentação anaeróbica realizada pela população bacteriana, transforma em produtos e fonte de energia (OWENS; GOETSCH, 1988; VAN SOEST et al., 1994).

No processo de ruminação realizado pelas bactérias fermentadoras de carboidratos estruturais, provenientes de fibras, amido e açúcares de plantas (BERGMAN, 1990), formam-se os ácidos graxos voláteis (AGV), sendo os principais o acetato ( $\mathrm{C} 2$, ou ácido acético), propionato ( $\mathrm{C} 3$, ou ácido propiônico) e butirato (C4, ou ácido butírico) (MORAN, 2005). Produzem também outros compostos, como a amônia $\left(\mathrm{NH}_{3}\right)$; dióxido de carbono $\left(\mathrm{CO}_{2}\right)$; metano $\left(\mathrm{CH}_{4}\right), \mathrm{H}_{2}$ (hidrogênio), lactato e álcool (VALADARES FILHO; PINA, 2011). Observa-se que na relação simbiótica entre ruminantes e microrganismos está envolvida a ineficiência energética (perda na forma de metano) e proteica (perda de $\mathrm{N}$ na forma de $\mathrm{NH}_{3}$ ) (CALSAMIGLIA, 2007). Segundo esse autor, a produção de metano representa uma perda de 2-12\% da energia consumida, mas pode ser variável entre 2-3\% segundo Johnson e Johnson (1995). As quantidades dos subprodutos, como $\mathrm{CO}_{2}$ e $\mathrm{H}_{2}$, são variáveis, dependendo da concentração e das proporções relativas dos AGV produzidos (OWENS; GOETSCH, 1988; EUN et al., 2004).

Hungate (1966) caracteriza em três equações a perda de hidrogênio e carbono para cada tipo de ácido graxo formado:

$$
\begin{aligned}
& 31 \text { hexose }+62 \mathrm{H}_{2} \mathrm{O} \rightarrow 62 \text { (Acético) }+62 \mathrm{CO}_{2}+124 \mathrm{H}_{2} \\
& 11 \text { hexose }+22 \mathrm{H}_{2} \rightarrow 22 \text { (Propiônico) }+22 \mathrm{H}_{2} \mathrm{O} \\
& 16 \text { hexose } \rightarrow 16 \text { (Butírico) }+32 \mathrm{CO}_{2}+32 \mathrm{H}_{2}
\end{aligned}
$$


Observamos que, de acordo com as proporções de 62,22 e $16 \%$ de produção dos AGV (equações 1 a 3) na utilização da hexose, a maior produção de $\mathrm{H}_{2}$ ocorre durante a produção do acetato (HEGARTY, 1999). Este resíduo de hidrogênio se encontra na forma de gás $\left(\mathrm{gH}_{2}\right)$ e $\mathrm{H}_{2}$ dissolvido $\left(\mathrm{dH}_{2}\right)$, sendo apenas a forma $\mathrm{dH}_{2}$ biologicamente disponíveis para as metanogênicas e participam do processo fermentativo (JANSSEN, 2010; COTTLE et al., 2011). O excesso de $\mathrm{H}_{2}$ no rúmen é eliminado pela microbiota metanogênica, principalmente do gênero Archae (BAKER, 1999), utilizando-se do $\mathrm{CO}_{2}$ e $\mathrm{H}_{2}$ como fonte de energia e formando como produto final deste processo o $\mathrm{CH}_{4}$ (KOZLOSKI, 2002; COTTLE et al., 2011). Embora várias espécies de metanogênicas tenham sido isoladas em diversos habitats anaeróbios, apenas cinco dessas espécies foram encontradas no rúmen, e destas apenas duas, Methanobrevibacter ruminantium e Methanosarcina sp., têm sido encontradas neste compartimento em populações maiores que $1 \times 10^{6} \mathrm{~mL}^{-1}$ (MCALLISTER et al., 1996).

Segundo Primavesi et al. (2015), uma das alternativas para redução da perda de energia na forma de metano ruminal é o uso de forragens com maior digestibilidade, corrigida com concentrado e uso de alimentos com menos fibra e maior fração digestível, como leguminosas. Portanto, uma forma de mitigar o $\mathrm{CH}_{4}$ ruminal é promover caminho metabólico alternativo em competição com os metanogênicos pelo uso de hidrogênio ruminal $\left(\mathrm{H}_{2}\right)$. Nesse sentido, uma das alternativas mais antigas é a introdução de ionóforo monensina na dieta. Ela diminui a produção de $\mathrm{H}_{2}$ pela redução do consumo voluntário dos animais, atua na modulação da flora ruminal alterando a proporção acetato:propionato, e na inibição da enzima formato-liase diminuindo a produção de $\mathrm{H}_{2}$ a partir do ácido fórmico (HEGARTY, 1999; TEDESCHI et al., 2003; MORAIS et al., 2006; RIVERA et al., 2010).

Em muitos países da Europa e na União Europeia, o uso de ionóforos não é permitido. Dessa forma, uma alternativa para manipulação da fermentação ruminal é pela suplementação lipídica na dieta (SULLIVAN et al., 2004; FIORENTINI et al., 2014). Também, o emprego de extratos vegetais ricos em allicina, taninos e saponinas têm demonstrado grande potencial na redução de metano entérico (MCALLISTER, 2008; PEN et al., 2008; PATRA; SAXENA, 2009; BHATTA et al., 2009). Portanto, o sistema de produção, o tipo de alimento, a adição de lipídeos, concentração de tanino e o 
uso de aditivos para manipulação ruminal são importantes componentes que afetam e estão envolvidos na produção de $\mathrm{CH}_{4}$ no rúmen (LASCANO; CARDENAS, 2010).

Conforme Ogle et al. (2014), o setor agrícola pode dar um grande passo associando as oportunidades de adaptação à mudança do clima e à mitigação das emissões de gases de efeito estufa com as opções promissoras de manejo na produção. Ainda, os autores propõem que os fatores de emissão mais precisos sejam desenvolvidos, baseados no desempenho da produção.

\section{CONSIDERAÇÕES FINAIS}

A Caatinga oferece grande variedade de espécies vegetais que em conjunto permitem a exploração de ruminantes, mas suas características nutricionais, principalmente na qualidade, e aspectos de sazonalidade na oferta de nutrientes devem ser levadas em consideração.

As implicações nutricionais da vegetação da Caatinga sugerem que a suplementação proteéica e/ou energética, e a adição de mineral, podem auxiliar na redução dos fatores responsáveis pela redução do desempenho animal neste bioma.

Do ponto de vista da emissão de metano ruminal, a diversidade da vegetação na Caatinga oferece oportunidade para exploração das espécies que apresentem menores taxas de emissão de metano e melhor desempenho animal. Além disso, é oportunidade única em obter a base referencial da emissão de metano ruminal associada aos aspectos nutricionais das forrageiras nativas aproveitadas pelos animais em pastejo.

O conhecimento da linha de referência (linha base) tanto da produtividade quanto de emissões envolvidas com as formas de produção utilizadas hoje na área da Caatinga possibilitará a identificação de opções de mitigação.

\section{REFERÊNCIAS}

ARAÚJO FILHO, J.A. Proposta para a implementação do manejo pastoril sustentável da Caatinga. Ministério do Meio Ambiente, 2014. 135 p. 
ARAÚJO FILHO, J.A.; CARVALHO, F.C.; GARCIA, R.; SOUSA, R.A. Efeitos da manipulação da vegetação lenhosa sobre a produção e compartimentalização da fitomassa pastável de uma Caatinga Sucessional. Revista Brasileira de Zootecnia, v. 31, n. 1, p. 11-19, 2002.

ARAÚJO FILHO, J.A.; CRISPIM, S.M.A. Pastoreio combinado de bovinos, caprinos e ovinos em áreas de Caatinga no Nordeste do Brasil. In: I Conferência Virtual Global sobre Produção Orgânica de Bovinos de Corte - Via Internet, em 02 de setembro a 15 de outubro de 2002.

BAKER, S.K. Rumen methanogens and inibition of methanogenesis. Australian Journal of Agricultural Research, v.50, n.8, p. 1293-1298, 1999.

BERGMAN, E.N. Energy contributions of volatile fatty acids from the gastrointestinal tract in various species. Physiological Reviews. v. 70, n. 2, p. 567-590, 1990.

BHATTA, R.; Y. UYENO, Y.; TAJIMA, K.; TAKENAKA, A.; YABUMOTO, Y.; NONAKA, I.; ENISHI, O.; KURIHARA, M. Difference in the nature of tannins on in vitro ruminal methane and volatile fatty acid production and on methanogenic Archaea and protozoal populations. Journal of Dairy Science, v. 92, p. 5512-5522, 2009.

BRASIL. Ministério da Ciência e Tecnologia - MCT. $3^{\text {a }}$ Comunicação Nacional do Brasil à Convenção-Quadro das Nações Unidas sobre Mudança do Clima: volume 3. Brasilia, DF, 2016. 336 p. Disponível em: http://sirene.mcti. gov.br/documents/1686653/1706739/Nolume +3.pdf/355d4a1e-9f3c-474a-982eb4a63312813b. Acesso em: 10 out 2016.

BRASIL. Ministério da Integração Nacional. Nova delimitação do semiárido brasileiro. 2005.

CABRAL, J.E.S. Fracionamento do nitrogênio e dos carboidratos de espécies encontradas na Caatinga do Rio Grande do Norte. 2014. 66F. Dissertação (Mestrado). Universidade Federal Rural do Semi-Árido, UFERSA, Mossoró, 2014, p.66.

CALSAMIGLIA, S.; BUSQUET, M.; CARDOZO, P.W.; L.CASTILLEJOS,L.; FERRET, A. Invited Review: Essential oils as modifiers of rumen microbial fermentation. Journal 
of Dairy Science, v. 90, p. 2580-2595, 2007.

CARULLA, J.E.; KREUZER, M.; MACHMÜLLER, A.; et al. Supplementation of Acacia mearnsii tannins decreases methanogenesis and urinary nitrogen in forage-fed sheep. Australian Journal of Agricultural Research, v. 56, p. 961-970, 2005.

CARVALHO JÚNIOR, A.M.; PEREIRA FILHO, J.M.; SILVA, R.M.; SILVA, A.M.A.; CEZAR, M.F. Effect of supplementation on the performance of $\mathrm{F} 1$ crossbred goats finished in native pasture. Revista Brasileira de Zootecnia, v. 40, n. 11, p. 2510-2517, 2011.

CHAVES, I. DE B.; LOPES, V. L.; FFOLLIOTT, P. F.; PAES-SILVA, A. P. Uma classificação morfo-estrutural para descrição e avaliação da biomassa da vegetação da caatinga. Revista Caatinga, v. 21, n.2, p.204-213, 2008.

COTTLE, D. J.; NOLAN, J.V.; WIEDEMANN, S. G. 2011. Ruminant enteric methane mitigation: A review. Animal Production Science, v. 51, n. 6, p. 491-514, 2011. $<$ doi:10.1071/AN10163>

CRUZ, S. E. S. B. S.; BEELEN, P. M. G.; SILVA, D. S.; PEREIRA, W. E.; BEELEN, R.; BELTRÃO, F. S. Caracterização dos taninos condensados das espécies maniçoba (Manibot pseudoglazovii), flor-de-seda (Calotropis procera), feijão-bravo (Capparis flexuosa, L) e jureminha (Desmanthus virgatus). Arquivo Brasileiro de Medicina Veterinária e Zootecnia, v. 59, n. 4, p. 1038-1044, 2007.

DRUMOND, M.A.; KIILL, L.H.P.; LIMA, P.C.F.; OLIVEIRA, M.C.; OLIVEIRA, V.R.; ALBUQUERQUE, S.G.; NASCIMENTO, C.E.S.; CAVALCANTI, J. Estratégias para o uso sustentável da biodiversidade da caatinga. In: Seminário para avaliação e identificação de ações prioritárias para a conservação, utilização sustentável e repartição de benefícios da biodiversidade do bioma Caatinga. Anais... EMBRAPA/CPATSA, UFPE e Conservation International do Brasil, Petrolina. 2000.

EUN, J.S.; FELLNER, V.; GUMPERTZ, M.L. Methane production by mixed ruminal cultures incubated in dualflow fermentors. Journal of Dairy Science, Savoy, v.87, p.112-121, 2004.

FAO - Food and Agriculture Organization of the United Nations: "Climate-Smart" Agriculture: Policies, Practices and Financing for Food Security, Adaptation 
and Mitigation. Rome; 2010.

FIORENTINI, G.; CARVALHO, I.P.C.; MESSANA, J.D.; CASTAGNINO, P.S.; BERNDT, A.; CANESIN, R.C.; FRIGHETTO, R.T.S.; BERCHIELLI, T.T. Effect of lipid sources with different fatty acid profiles on the intake, performance, and methane emissions of feedlot Nellore steers. Journal of Animal Science, v. 92, p. 1613-1620, 2014.

GOUVELLO, C.; SOARES FILHO, B.S.; NASSAR, A.; SCHAEFFER, R.; ALVES, F.J.; ALVES, J.W.S. Brazil low carbon country case study. The International Bank for Reconstruction and Development / The World Bank. 2010. 286p. Disponível em $<$ www.worldbank.org $>$ ou <www.esmap.org $>$

HEGARTY, R.S. Mechanisms for competitively reducing ruminal methanogenesis. Australian Journal of Agricultural Research, v. 50, p. 1299-1305, 1999.

HOOK, S.E.; WRIGHT, A.D.G.; McBRIDE, B.W. Methanogens: methane producers of the rumen and mitigation strategies. Archaea, p.1-11, 2010.

HUNGATE, R.E. The Rumen and its Microbes. Academic Press Inc., New York; 1966.

JACOBSON, T.K.B.; GARCIA, J.; SANTOS, S.C. et al. Influência de fatores edáficos na produção de fenóis totais e taninos de duas espécies de barbatimão (Stryphnodendron sp.). Pesquisa Agropecuária Tropical, n. 35, v. 3, p. 163-169, 2005.

JANSSEN, P. H. 2010. Influence of hydrogen on rumen methane formation and fermentation balances through microbial growth kinetics and fermentation thermodynamics. Animal Feed Science and Technology, v. 160, n. 1-2, p. 1-22, 2010. <doi:10.1016/j.anifeedsci.2010.07.002>

JOHNSON, K.A.; JOHNSON D.E. Methane emissions from cattle. Journal of Animal Science, v.73, n. 8, p. 2483-2492,1995.

KEBREAB, E.; STRATHE, A.; FADEL, J.; MORAES, L.; FRANCE, J. Impact of dietary manipulation on nutrient flows and greenhouse gas emissions in cattle. Revista Brasileira de Zootecnia, v.39, p.458-464, 2010.

KÖPPEN, W. Das geographische system der klimate. In: KÖPPEN. W., GEIGER, R. Handbuch der klimatologie. Berlim. Verlag von Gebrüder Borntlaeger, v.1, part 
c. 1936.

KOZLOSKI, G.B. Bioquímica dos ruminantes. Santa Maria: Universidade Federal de Santa Maria, 2002. 139p.

LANA, R.P.; RUSSELL, J.B.; Van AMBURGH, M.E. The role of $\mathrm{pH}$ in regulating ruminal methane and ammonia production. Journal of Animal Science, v.76, p.2190-2196, 1998.

LASCANO, C.E.; CÁRDENAS, E. Alternatives for methane emission mitigation in livestock systems. Revista Brasileira de Zootecnia, v. 39, p. 175-182, 2010.

LASSEY, K.R. Livestock methane emission and its perspective in the global methane cycle. Australian Journal of Experimental Agriculture, v.48, p.114-118, 2008.

LEITE, E.R.; CÉSAR, M.F.; ARAÚJO FILHO, J.A. Efeitos do melhoramento da Caatinga sobre os balanços protéico e energético na dieta de ovinos. Ciência Animal, v.1, n. 12, p. 67-73, 2002.

LIMA JÚNIOR, V. Caracterização da dieta e avaliação de métodos de estimativa de consumo em caprinos suplementados na caatinga. 2006. 85f. Dissertação (Mestrado). Universidade Federal da Paraíba, João Pessoa, 2006. p.85.

LIMA, J.L.S. Plantas forrageiras das caatingas: usos e potencialidades. Petrolina: Embrapa-CPATSA, PNE: RBG-KEW, 1996. 44p.

MARQUES, C.A.T.; MEDEIROS, A.N.D.; COSTA, R.G.; CARVALHO, F.F.R.; ARAÚJO, M.J.; TORREÃO, J.N.C. Performance and carcass traits of Moxotó growing goats supplemented on native pasture under semiarid conditions. Revista Brasileira de Zootecnia, v. 43, n. 3, p. 151-159, 2014.

MENEZES, R.S.C.; SAMPAIO, E.V.S.B. Agricultura sustentável no Semi-árido nordestino. In: OLIVEIRA, T.S.; ROMERO, R.E.; ASSIS JÚNIOR, R.N.; SILVA, J.R.C.S. (Ed.). Agricultura, sustentabilidade e o Semiárido. Fortaleza: SBCS: UFC-DCS, 2000. p.20-46.

MENG, Q.X.; XIA, Z.G.; KERLEY, M.S. The requirement of ruminal degradable protein for non-structural carbohydrate-fermenting microbes and its relation with dilution 
rate in continuous culture. Asian-Australasian Journal of Animal Science, v. 13, n. 10, p. 1399-1406, 2000. < doi: https://doi.org/10.5713/ajas.2000.1399>

MOLANO, G.; CLARK, H., The effect of level of intake and forage quality on methane production by sheep. Australian Journal of Experimental Agriculture, v.48, p.219-222, 2008.

MONTEIRO, J.M.; ALBUQUERQUE, U.P.; LINS NETO, E.; ARAÚJO, E.L.; ALBUQUERQUE, M.M.; AMORIM, E.L.C. The effects of seasonal climate changes in the caatinga on tannin levels in Myracrodruon urundeuva (Engl.) Fr. All. and Anadenanthera colubrina (Vell.) Brenan. Revista brasileira de farmacologia, v. 16, n. 3, p. 338-344, 2006.

MORAIS, J.A.S.; BERCHIELLI, T.T.; REIS, R.A. Aditivos. In: BERCHIELLI, T.T.; PIRES, A.V.; OLIVEIRA, S.G. (Eds.) Nutrição de ruminantes. 1.ed. Jaboticabal: Funep, 2006. p.539-570.

MORAN, J. Tropical dairy farming: Feeding management for small holder dairy farmers in the humid tropics. CSIRO Publishing, 2005. 295p.

MOREIRA, J.N.; LIRA, M.A.; SANTOS, M.V.F. et al. Caracterização da vegetação de Caatinga e da dieta de novilhos no Sertão de Pernambuco. Pesquisa Agropecuáaria Brasileira, v.41, n.11, p.1643-1651, 2006.

NEGRA, C.; VERMEULEN, S.; BARIONI, L.G.; MAMO, T.; MELVILLE, P.; TADESSE, M. Brazil, Ethiopia and New Zealand lead the way on climate-smart agriculture. Agriculture \& Food Security, vol. 3, p. 19-24, 2014.

OGLE, S.M.; OLANDER, L.; WOLLENBERG, L.; ROSENSTOCK, T., TUBIELLO, F.; PAUSTIAN, K.; BUENDIA, L.; NIHART, A.; SMITH, P. Opinion: Reducing greenhouse gas emissions and adapting agricultural management for climate change in developing countries: providing the basis for action. Global Change Biology, v. 20, p. 1-6, 2014. < doi: 10.1111/gcb.12361>

OWENS, F.N.; GOETSCH, A.L. Ruminal fermentation. In: CHURCH, D.C. (Ed) The ruminant animal: digestive physiology and nutrition. Waveland Press, 1988. p.145-171. 
PATRA, A.K.; SAXENA, J. Dietary phytochemicals as rumen modifiers: a review of the effects on microbial populations. Antonie van Leeuwenhoek, v. 96, p. 363-375, 2009.

PEN, B.; SAR, C.; MWENYA, B.; TAKAHASHI, J. Effects of Quillaja saponaria extract alone or in combination with Yucca schidigera extract on ruminal fermentation and methanogenesis in vitro. Animal Science Journal, v. 79, p. 193-199, 2008.

PEREIRA JÚNIOR, L.R.; ANDRADE, A.P.; ARAÚJO, K.D. composição florística e fitossociológica de um fragmento de caatinga em Monteiro, PB. Holos, n. 28, v. 6, p. 73-87, 2012.

PRIMAVESI, O.; BERNDT, A.; LIMA, M.A.; et al. Produção de gases de efeito estufa em sistemas agropecuários. Bases para inventário de emissão de metano por ruminantes, p. 231-265. In: Estoques de Carbono e emissões de gases de efeito estufa na agropecuária brasileira. Lima, M.A.; Boddey, R.M.; Alves, B.J.R.; Machado, P.L.O. de A.; Urquiaga, S. (eds). $3^{\text {a }}$ ed. rev. - Brasília, DF: Embrapa, 2015. 343 p.

PUCHALA, R.; MIN, B.R.; GOETSCH, A.L.; SAHLU, T. The effect of a condensed tannincontaining forage on methane emission by goats. Journal of Animal Science. V. 83, p. 182-186. 2005.

RIVERA, A.R.; BERCHIELLI, T.T.; MESSANA, J.D.; VELASQUEZ, P.T.; FRANCO, A.V.M.; FERNANDES. L.B. Fermentação ruminal e produção de metano em bovinos alimentados com feno de capim-tifton 85 e concentrado com aditivos. Revista Brasileira de Zootecnia, v.39, n.3, p.617-624, 2010.

ROSENSTOCK, T.S.; RUFINO, M.C.; BUTTERBACH-BAHL, K.; WOLLENBERG, E. Toward a protocol for quantifying the greenhouse gas balance and identifying mitigation options in smallholder farming systems. Environmental Research Letters, vol. 8, p. 2-6, 2013.

RUSSELL, J.B.; O'CONNOR, J.D.; FOX, D.G.; VAN SOEST, P.J.; SNIFFEN, C.J. A net carbohydrate and protein system for evaluating cattle diets: I. ruminal fermentation. Journal of Animal Science, v. 70, p. 3551-3561,1992.

RUSSELL, J.B.; SHARP, W.M.; BALDWIN, R.L. The effect of pH on maximum bacterial 
growth rate and its possible role as a determinant of bacterial competition in the rumen. Journal of Animal Science, v.48, p.251-258, 1979.

RUSSELL, J.B.; STROBEL, H.J.; CHEN, G. The enrichment and isolation of a ruminal bacterium with a very high specific activity of ammonia production. Applied and Environmental Microbiology, v.54, p.872-877, 1988.

SANTOS, M.V.F.D.; LIRA, M.D.A.; JUNIOR, D. et al.. Potential of Caatinga forage plants in ruminant feeding. Revista Brasileira de Zootecnia, v. 39, p. 204-215, 2010 .

SARVANAN, T.S. Effect of bromochloromethane on methanogenesis, nutrient utilization and growth rate of lambs. MVSc Thesis, Indian Veterinary Research Institute, Izatnagar, India. 2000

SNIFFEN, C.J.; O’CONNOR, J.D.; VAN SOEST, P.J.; FOX, D.G.; RUSSELL, J.B. A net carbohydrate and protein system for evaluation of cattle diets:II. Carbohydrate and protein availability. Journal of Animal Science, v. 70, n. 11, p. 3562-3577, 1992.

SOUZA, C.; BARRETO, H.F.; GURGEL, V.; COSTA, F. Disponibilidade e valor nutritivo da vegetação de Caatinga no Semiárido Norte Riograndense do Brasil. Holos, ano 29, v. 3, 2013.

SOUZA, C.M.S.; MEDEIROS, A.N.; COSTA, R.G.; SALES. E.P.; SILVA, A.M.A.; LIMA JÚNIOR, V. Micromineral nutritional requirements for weight gain in Canindé goats under grazing in the brazilian semiarid. Acta Scientiarum, Maringá, v. 35, n. 2, p. 173-179, 2013.

SUlLIVAN, H. M.; BERNARD, J.K.; AMOS, H.E.; JENKINS, T.C. Performance of lactating dairy cows fed whole cottonseed with elevated concentrations of free fatty acids in the oil. Journal of Dairy Science, v. 87, p. 665-671, 2004.

TEDESCHI, L.O.; FOX D.G.; TYLUTKI, T.P. Potential environmental benefits of ionophores in ruminant diets. Journal Environmental Quality, v.32, n.7, p.1591$1602,2003$.

TELES, M. M. F.; ANDRADE, A.P.; ROSA, P.R.O. Delimitação espacial da vegetação do município de São João do Cariri- PB através de classificação de imagem orbital. 
Geografia, v. 15, n. 1, p. 81-93, 2006.

TIEMANN, T.T.; LASCANO, C.E.; WETTSTEIN, H. R. et al. Effect of the tropical tannin-rich shrub legumes Calliandra calothyrsus and Flemingia macrophylla on methane emission and nitrogen and energy balance in growing lambs. Animal, v. 2, p. 790-799, 2008.

USEPA - US ENVIROMENTAL PROTECTION AGENCY - ESTADOS UNIDOS. Greenhouse gas emissions from agricultural systems, v. 1, Summary Report. WORKSHOP ON GREENHOUSE GAS EMISSIONS FROM AGRICULTURE, 1990, Washington. Proceedings... Washington, DC, 1990a.

USEPA - US ENVIROMENTAL PROTECTION AGENCY - ESTADOS UNIDOS. Methane emissions and opportunities for control. WORKSHOP RESULTS OF INTERGOVERNMENTAL PANEL ON CLIMATE CHANGE, 1990, Washington. Proceedings... Washington, DC, 1990b.

VALADARES FILHO, S.C.; PINA, D.S. Fermentação ruminal. In: BERCHIELLI, T.T; PIRES, A.V.; OLIVEIRA, S.G. (Ed.). Nutrição de ruminantes. 2. ed. Jaboticabal: FUNEP, 2011. p. 291-322.

VAN SOEST, P.J. Nutritional ecology of the ruminant. 2. ed. Ithaca: Cornell University Press, 1994. 476p.

WATERS, C.J. Problems associated with estimating the digestibility of undergrated dietary nitrogen from acid-detergent insoluble nitrogen. Animal Feed Science and Technology, Amsterdam, v. 39, n. 3, p. 279-291, 1992.

WEIMER, P.J. Manipulating ruminal fermentation: a microbial e ecological, perspective. Journal of Animal Science, Savoy, v. 76, p. 3114-3122, 1998.

Recebido em: 19/03/2016 Acesso em: 17/04/2017 